Supporting Information

\title{
Nature of the Active Catalyst in the Hafnium-Pyridyl Amido- Catalyzed Alkene Polymerization
}

\author{
Eric S. Cueny, ${ }^{\dagger \S}$ Megan R. Nieszala, ${ }^{\dagger}$ Robert D. J. Froese,${ }^{\ddagger}$ and Clark R. Landis ${ }^{\dagger \star}$ \\ †Department of Chemistry, University of Wisconsin-Madison, 1101 University Avenue, Madison, \\ Wisconsin 53706, United States \\ ¥Core R\&D, The Dow Chemical Company, 1776 Building, Midland, Michigan 48674, United States
}

\section{Corresponding Author \\ *landis@chem.wisc.edu}

\section{Current Address}

§E.S.C.: Department of Chemistry, University of Pennsylvania, 231 S 34th St, Philadelphia, PA 19104.

\section{Contents}

General experimental considerations

Preactivation Protocol for rac-1 using Trityl

in situ Activation Protocol for rac-1 using Trityl

in situ Activation Protocol for 2 using $\mathrm{B}\left(\mathrm{C}_{6} \mathrm{~F}_{5}\right)_{3}$

in situ Activation Protocol for rac-1 using $\mathrm{B}\left(\mathrm{C}_{6} \mathrm{~F}_{5}\right)_{3}$

Procedure for Mass Spectrometric Analysis of Ligands Post-Polymerization

Amine Inhibition of rac-1 Polymerizations Preactivated with Trityl

General Kinetic Modeling Considerations

Mass Spectrometry Results

S-4

Amine Inhibition and Kinetic Modeling Results

Raw Data Used for Kinetic Modeling

in situ Activation of rac-1 with $\mathrm{B}\left(\mathrm{C}_{6} \mathrm{~F}_{5}\right)_{3}$

Molecular Weight Distribution Data for $2 / \mathrm{B}\left(\mathrm{C}_{6} \mathrm{~F}_{5}\right)_{3}$-Catalyzed Polymerization of

1-Hexene

References 


\section{General experimental considerations}

Unless noted otherwise, all manipulations were performed under air- and moisture-free conditions using standard Schlenk-line and glovebox techniques. Compounds $\operatorname{rac}-\mathbf{1},{ }^{1} \mathbf{2}^{2}{ }^{2}$ and $\mathbf{3}^{3}$ were prepared according to literature procedures. Toluene was purified by passage through a column of activated alumina and a column of supported copper catalyst (Q-5). 1-Octene and 1-hexene were purified by distillation over $\mathrm{Na}$ followed by freeze-pump-thaw. All other compounds were commercial products and used as received. Stock solutions of rac-1, 2, 3, $\left[\mathrm{Ph}_{3} \mathrm{C}\right]\left[\mathrm{B}\left(\mathrm{C}_{6} \mathrm{~F}_{5}\right)_{4}\right]$, $\mathrm{B}\left(\mathrm{C}_{6} \mathrm{~F}_{5}\right)_{3}$, and $\left[\mathrm{HNMe}\left(\mathrm{C}_{18} \mathrm{H}_{37}\right)_{2}\right]\left[\mathrm{B}\left(\mathrm{C}_{6} \mathrm{~F}_{5}\right)_{4}\right]$ in toluene were prepared and stored in a $\mathrm{N}_{2}$-atmosphere glovebox. The stock solutions of $\left[\mathrm{Ph}_{3} \mathrm{C}\right]\left[\mathrm{B}\left(\mathrm{C}_{6} \mathrm{~F}_{5}\right)_{4}\right]$ and $\mathrm{B}\left(\mathrm{C}_{6} \mathrm{~F}_{5}\right)_{3}$ were remade weekly. General NMR spectra were collected using a Bruker Avance $400 \mathrm{MHz}$ instrument fitted with a Smartprobe, Avance $500 \mathrm{MHz}$ instrument fitted with a DCH cryoprobe, or Avance 600 with TCl-F cryoprobe. Quantitative ${ }^{1} \mathrm{H}$ NMR spectra measuring monomer consumption were collected using a relaxation delay of 25 s. GPC analyses were performed using a Viscotek GPCmax/VE 2001 instrument fitted with PolyPore columns $(2 \times 300 \times 7.5 \mathrm{~mm})$ featuring $5 \mu \mathrm{m}$ particle size from Polymer Laboratories. Samples were eluted with THF at a flow rate of $1 \mathrm{~mL} / \mathrm{min}$ at $40^{\circ} \mathrm{C}$. Polymers were characterized by differential refractive index $(\mathrm{RI})$ and UV $(\lambda 344 \mathrm{~nm})$ detection using a Viscotek Model 302-050 Tetra Detector Array. Omnisec software (Viscotek, Inc.) was used for initial data processing such as positioning the baseline, setting limits, and applying the molecular weight calibration relative to ten polystyrene standards; EasiCal polystyrene standards with a MW range $580-377,400$ were purchased from Polymer Laboratories. Further processing was carried out in Microsoft Excel. Mass spectrometry was performed on a Thermo $Q$ Exactive Plus instrument. All polymerization reactions were carried out inside a $\mathrm{N}_{2}$-atmosphere glovebox.

\section{Preactivation Protocol for rac-1 using Trityl}

The reactions were conducted in standard $2 \mathrm{~mL}$ vials, unless otherwise specified. In a typical experiment, $92 \mu \mathrm{L}$ of a $0.00901 \mathrm{M}$ toluene solution of rac-1 was combined with $134.4 \mu \mathrm{L}$ of a $0.00542 \mathrm{M}$ toluene solution of $\left[\mathrm{Ph}_{3} \mathrm{C}\right]\left[\mathrm{B}\left(\mathrm{C}_{6} \mathrm{~F}_{5}\right)_{4}\right]$ (i.e. a 1:1.1 mixture of rac-1: $\left.\left[\mathrm{Ph}_{3} \mathrm{C}\right]\left[\mathrm{B}\left(\mathrm{C}_{6} \mathrm{~F}_{5}\right)_{4}\right]\right)$. The mixture was heated at $50{ }^{\circ} \mathrm{C}$ for 3 minutes in an aluminum heating block to form I. $26 \mu \mathrm{L}$ of this solution was sampled and added to a vial containing 1-octene $(0.5032 \mathrm{M})$ in toluene $(1 \mathrm{~mL})$ at 50 ${ }^{\circ} \mathrm{C}$ to initiate the polymerization. Reactions were quenched using 2 eq of 2 (relative to rac-1). Internal standard, $\mathrm{CH}_{2} \mathrm{Ph}_{2}(36 \mu \mathrm{mol})$, was added to the reaction vials. Aliquots were sampled for analysis by ${ }^{1} \mathrm{H}$ NMR spectroscopy in $\mathrm{CDCl}_{3}$ to obtain monomer consumption. The polyoctene samples (including the NMR samples) were prepared for GPC analysis by dilution up to $10 \mathrm{~mL}$ with THF and further diluted such that a $1 \mathrm{mg} / \mathrm{mL}$ concentration of polyoctene was achieved.

\section{in situ Activation Protocol for rac-1 using Trityl}

These polymerization reactions were conducted according to the above general polymerization procedure with the exception that rac-1 and $\left[\mathrm{Ph}_{3} \mathrm{C}\right]\left[\mathrm{B}\left(\mathrm{C}_{6} \mathrm{~F}_{5}\right)_{4}\right]$ were not heated together prior to initiation of polymerization. Instead, rac-1 was added to a vial containing 1 -octene $(0.5032 \mathrm{M})$ and $\left[\mathrm{Ph}_{3} \mathrm{C}\right]\left[\mathrm{B}\left(\mathrm{C}_{6} \mathrm{~F}_{5}\right)_{4}\right](0.0912 \mathrm{mM})$ in toluene $(1 \mathrm{~mL})$ at $50{ }^{\circ} \mathrm{C}$ to initiate the polymerization. The rest of the procedure mimics the general polymerization procedure. 


\section{in situ Activation Protocol for 2 using $\mathrm{B}\left(\mathrm{C}_{6} \mathrm{~F}_{5}\right)_{3}$}

These polymerization reactions were run according to the above general polymerization procedure with the exception that 2 and $B\left(\mathrm{C}_{6} \mathrm{~F}_{5}\right)_{3}$ were not heated together prior to initiation of polymerization. Instead, $2(0.5 \mu \mathrm{mol})$ was added to a vial containing 1-hexene $(0.750 \mathrm{M})$ and $\mathrm{B}\left(\mathrm{C}_{6} \mathrm{~F}_{5}\right)_{3}(0.525 \mathrm{mM})$ in toluene $(1 \mathrm{~mL})$ at $25^{\circ} \mathrm{C}$ (room temperature) to initiate the polymerization. The rest of the procedure mimics the general polymerization procedure.

\section{in situ Activation Protocol for rac-1 using $\mathrm{B}\left(\mathrm{C}_{6} \mathrm{~F}_{5}\right)_{3}$}

This procedure mimics the in situ activation protocol for 2 and $B\left(\mathrm{C}_{6} \mathrm{~F}_{5}\right)_{3}$ except that rac-1 is used as the catalyst.

\section{Procedure for Mass Spectrometric Analysis of Ligands Post-Polymerization}

These polymerization reactions were conducted according to the general polymerization procedure. The only exception being that reactions were quenched with 2 eq (relative to $[\mathrm{Hf}]$ ) of stearic acid instead of 3. Upon quenching and removing the reaction from the glovebox, the solvent was removed in vacuo and the ligands were extracted from the polyoctene sample with $\mathrm{MeOH}(2 \mathrm{~mL})$. The $\mathrm{MeOH}$ was removed in vacuo and an ether/ $\mathrm{H}_{2} \mathrm{O}$ (2 $\mathrm{mL}$ each) extraction performed. The ether layer was filtered through a small silica plug and dried in vacuo before submitting samples for mass spectrometry analysis. This analysis was used to identify the presence of ligand modifications (observed as the protonated cation) post-polymerization.

\section{Amine Inhibition of rac-1 Polymerizations Preactivated with Trityl}

These polymerization reactions were carried out according to the general polymerization procedure involving preactivation of rac-1 with $\left[\mathrm{Ph}_{3} \mathrm{C}\right]\left[\mathrm{B}\left(\mathrm{C}_{6} \mathrm{~F}_{5}\right)_{4}\right]$ with the exception that $\mathrm{NMe}\left(\mathrm{C}_{18} \mathrm{H}_{37}\right)_{2}$ was added to the activated catalyst solution. In a typical experiment, $92 \mu \mathrm{L}$ of a $0.00901 \mathrm{M}$ toluene solution of rac-1 was combined with $134.4 \mu \mathrm{L}$ of a $0.00542 \mathrm{M}$ toluene solution of $\left[\mathrm{Ph}_{3} \mathrm{C}\right]\left[\mathrm{B}\left(\mathrm{C}_{6} \mathrm{~F}_{5}\right)_{4}\right]$ (i.e. a 1:1.1 mixture of rac-1: $\left.\left[\mathrm{Ph}_{3} \mathrm{C}\right]\left[\mathrm{B}\left(\mathrm{C}_{6} \mathrm{~F}_{5}\right)_{4}\right]\right)$. The mixture was heated at 50 ${ }^{\circ} \mathrm{C}$ for 3 minutes in an aluminum heating block to form I. Various, carefully measured amounts of $\mathrm{NMe}\left(\mathrm{C}_{18} \mathrm{H}_{37}\right)_{2}(0-1$ eq) were added to the activated catalyst solution. The I / amine toluene solution was sampled and added to a vial containing 1-octene $(0.5032 \mathrm{M})$ in toluene $(1 \mathrm{~mL})$ at 50 ${ }^{\circ} \mathrm{C}$ to initiate the polymerization. After ten seconds of polymerization, 2 eq of 3 (relative to $[\mathrm{Hf}] 0$ ) to halt polymerization. The rest of the protocol mimics the general polymerization procedure.

\section{General Kinetic Modeling Considerations}

Herein, we use the program Copasi for the kinetic modeling and kinetic simulations in this manuscript. The reactions for the kinetic models were constructed in Copasi. Initial concentrations and time course data were used to perform optimizations for the kinetic model. We use the Levenberg-Marquardt method for parameter estimation in Copasi. 


\section{Mass Spectrometry Results}

a)

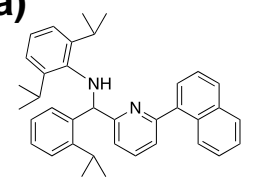

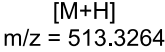

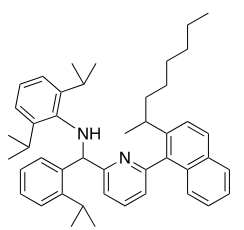

$\mathrm{m} / \mathrm{z}=625.4516$ b)

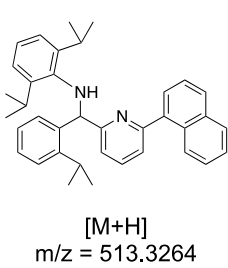

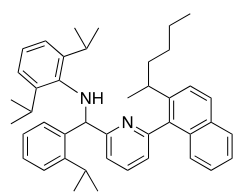

$m / z=597.4203$ c)

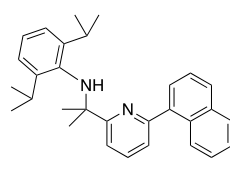

$[\mathrm{M}+\mathrm{H}]$
$\mathrm{m} / \mathrm{z}=423.2795$

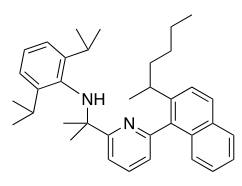

$\mathrm{m} / \mathrm{z}=507.3734$

Figure S1. All of the ligand fragments observed by mass spectrometry. (a) The homopolymerization of 1-octene catalyzed by rac-1. (b) The homopolymerization of 1-hexene catalyzed by rac-1. (c) The homopolymerization of 1 -hexene catalyzed by 2 .

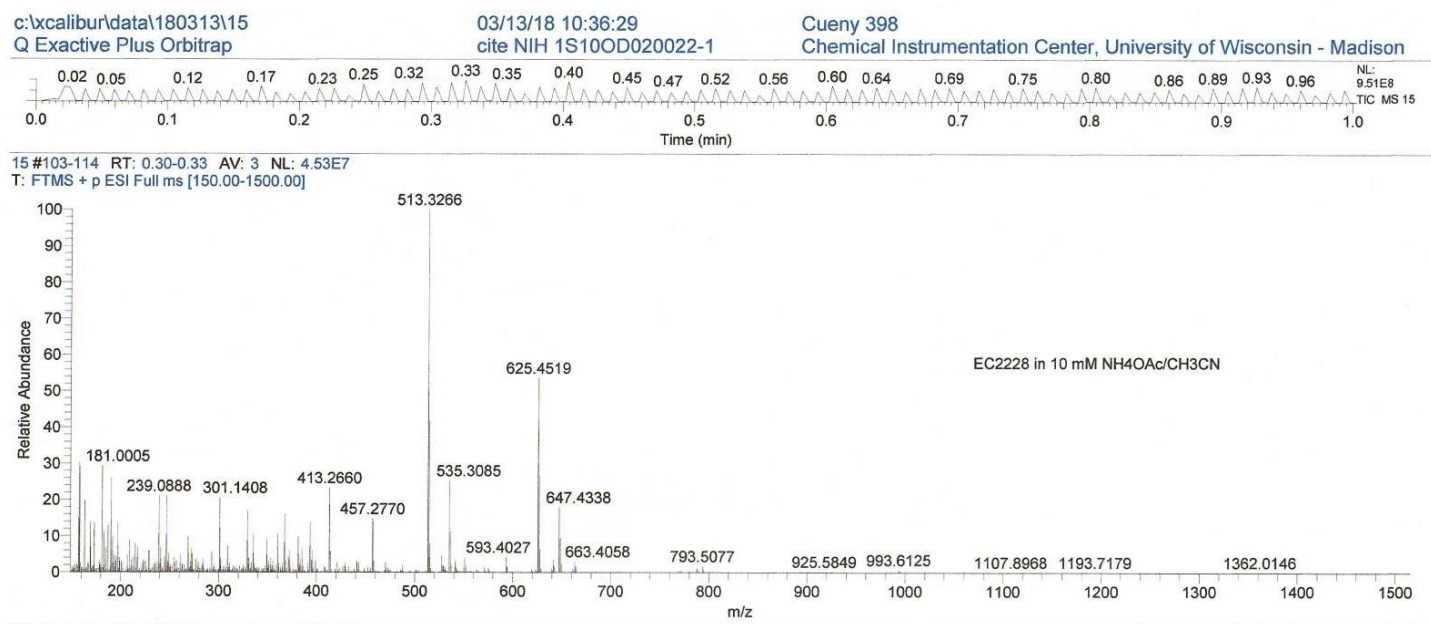

Figure S2. The mass spectrum of the homopolymerization of 1-octene catalyzed by rac-1 using the trityl preactivation protocol quenched with stearic acid after $120 \mathrm{~s}$ where $\sim 50 \%$ active site counts are observed. The $[\mathrm{M}+\mathrm{H}]^{+} \mathrm{m} / \mathrm{z}$ peaks of interest are 513.3266 and 625.4519 and the $[\mathrm{M}+\mathrm{Na}]^{+} \mathrm{m} / \mathrm{z}$ peaks of interest are 535.2085 and 647.4338 . 


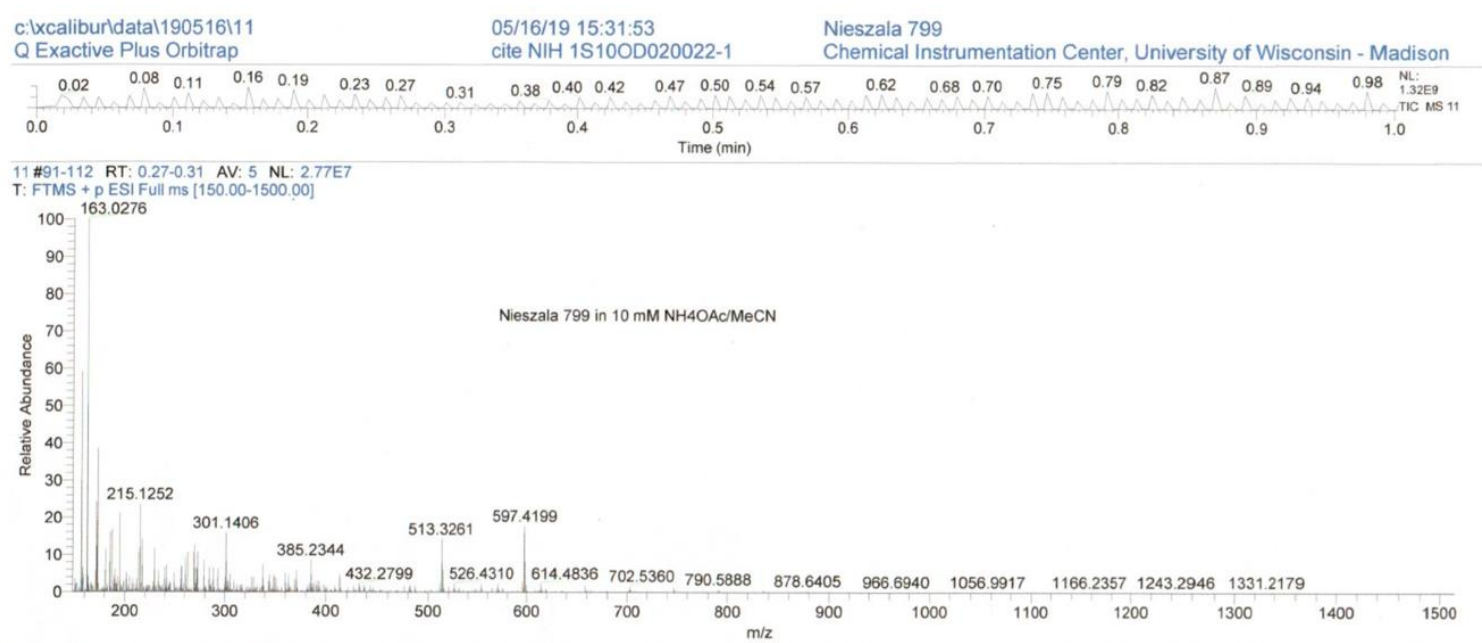

Figure S3. The mass spectrum of the homopolymerization of 1-hexene catalyzed by rac-1 using the trityl preactivation protocol quenched with stearic acid after $120 \mathrm{~s}$ where $~ 50 \%$ active site counts are observed. The $[\mathrm{M}+\mathrm{H}]^{+} \mathrm{m} / \mathrm{z}$ peaks of interest are 513.3261 and 597.4199 .

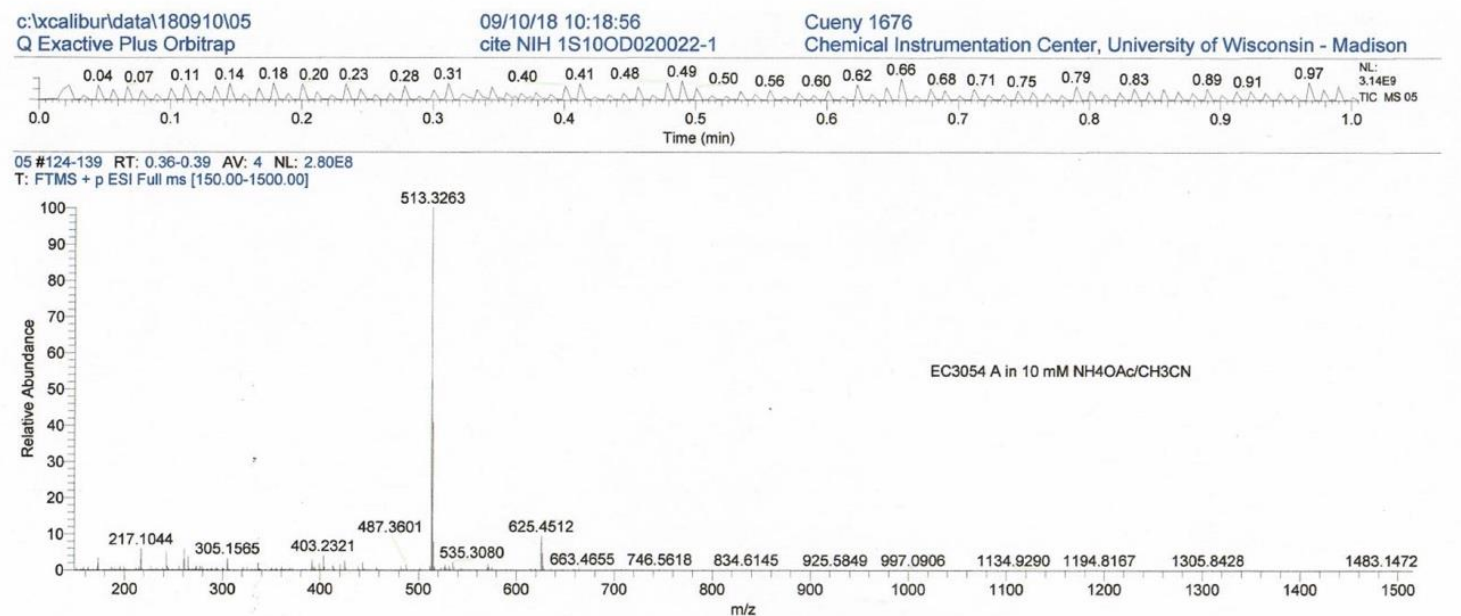

Figure S4. The mass spectrum of the homopolymerization of 1-octene catalyzed by rac-1 using the trityl in situ activation protocol quenched with stearic acid after $60 \mathrm{~s}$ where $~ 10 \%$ active site counts are observed. The $[\mathrm{M}+\mathrm{H}]^{+} \mathrm{m} / \mathrm{z}$ peaks of interest are 513.3263 and 625.4512 and the $[\mathrm{M}+\mathrm{Na}]^{+} \mathrm{m} / \mathrm{z}$ peak of interest is 535.3080 . 


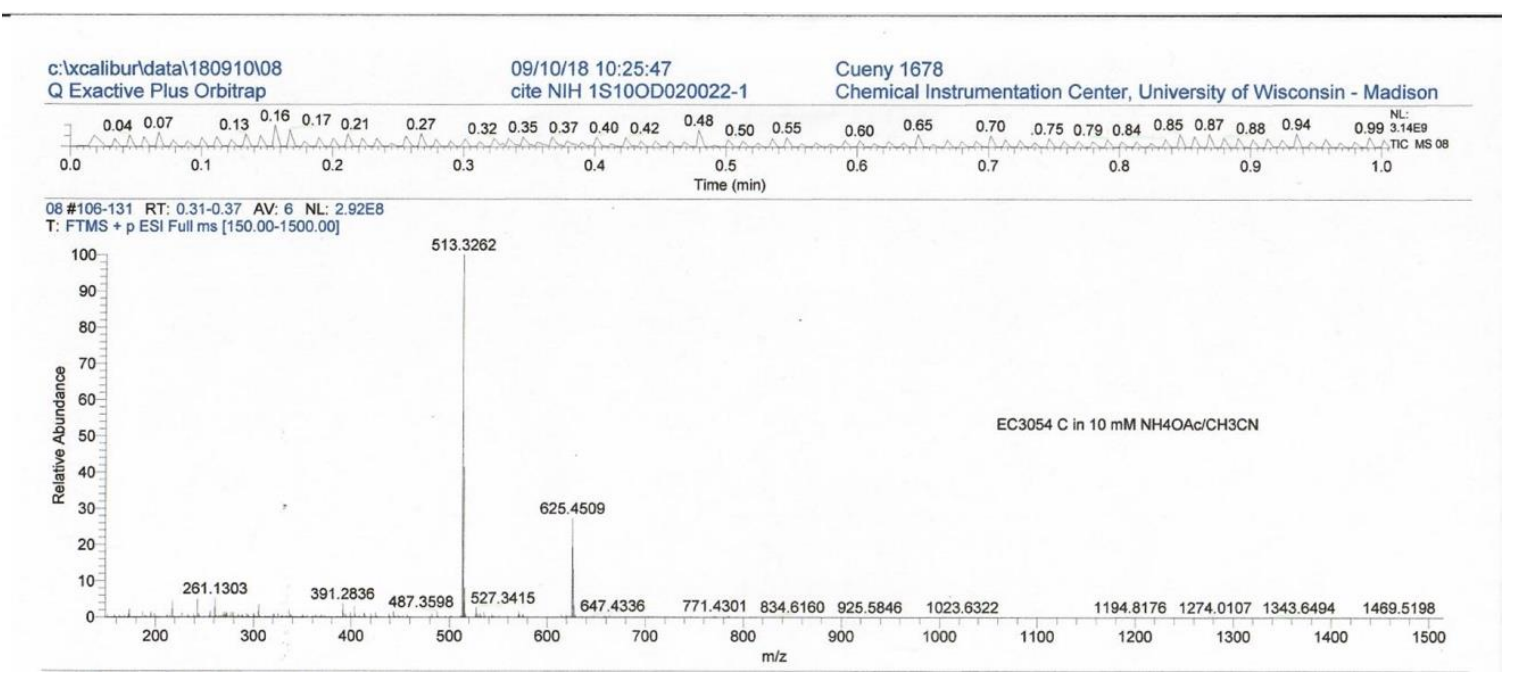

Figure S5. The mass spectrum of the homopolymerization of 1-octene catalyzed by rac-1 using the trityl in situ activation protocol quenched with stearic acid after $120 \mathrm{~s}$ where $~ 20 \%$ active site counts are observed. The $[\mathrm{M}+\mathrm{H}]^{+} \mathrm{m} / \mathrm{z}$ peaks of interest are 513.3262 and 625.4509 and the $[\mathrm{M}+\mathrm{Na}]^{+} \mathrm{m} / \mathrm{z}$ peaks of interest is 647.4336 . 
a)

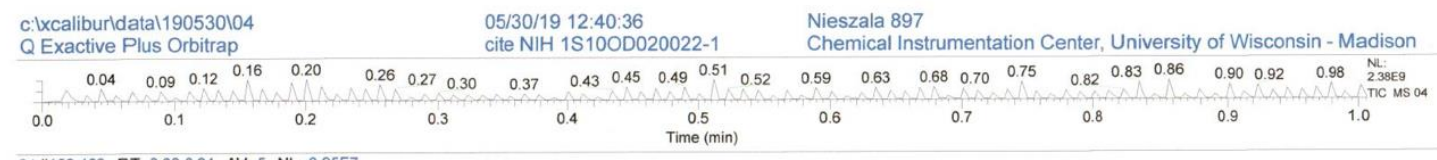

04 \#102-123 RT: $0.30-0.34$ AV: 5 NL: $8.95 E 7$
T: FTMS + p ESI Full ms [150.00-1500.00]
423.2787

100

90

\begin{tabular}{l|l}
80 & 507.3727
\end{tabular}

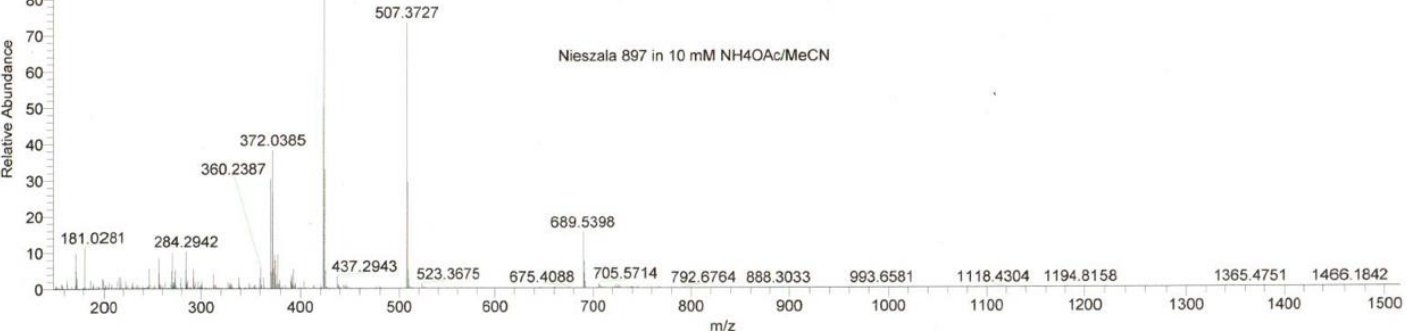

b)

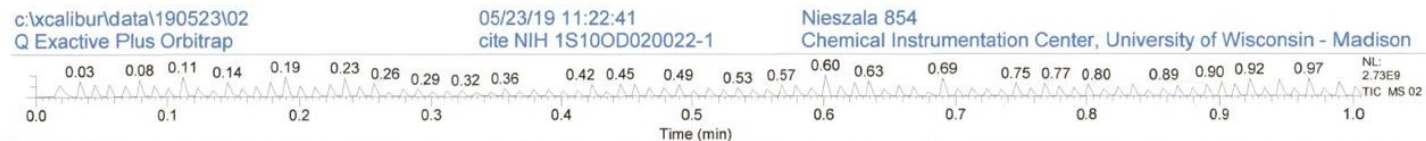

02\#104-122 RT: $0.30-0.35$ AV: 5 NL: $1.02 E 8$

T: FTMS + p ESI Full ms $[150.00-1500.00]$

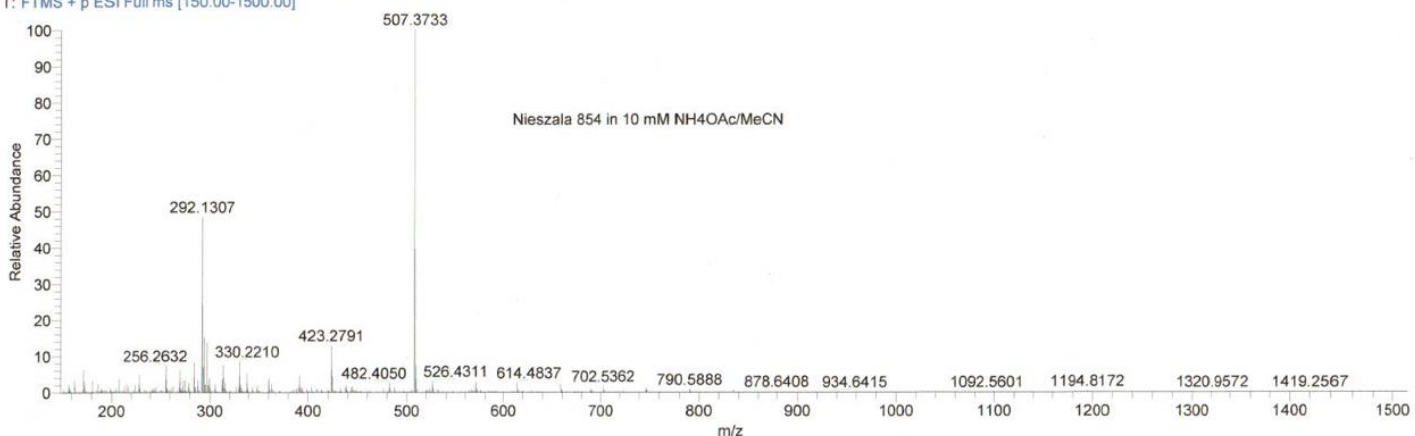

Figure S6. The mass spectra of the homopolymerization of 1-hexene catalyzed by 2 at room temperature using the $\mathrm{B}\left(\mathrm{C}_{6} \mathrm{~F}_{5}\right)_{3}$ activator. (a) Polymerization quenched with stearic acid after 1 minute of polymerization where active site counts are $\sim 30 \%$. The $[\mathrm{M}+\mathrm{H}]^{+} \mathrm{m} / \mathrm{z}$ peaks of interest are 423.2787 and 507.3727. (b) Polymerization quenched with stearic acid after 15 minutes of polymerization where active site counts are $~ 90 \%$. The $[\mathrm{M}+\mathrm{H}]^{+} \mathrm{m} / \mathrm{z}$ peaks of interest are 423.2791 and 507.3733. 


\section{Amine Inhibition and Kinetic Modeling Results}

To better understand the inhibition of amine, we developed a simple two-state model for amine inhibition using the kinetic modeling software Copasi. In this model (Figure S7), we assume that the CatA diastereomer of $\mathbf{I}$ has poor polymerization activity and binds amine rapidly and irreversibly but the CatB diastereomer is active for polymerization and binds the amine reversibly. By fixing the amine binding rate constant, $\mathrm{k}_{\mathrm{a}}$, of the kinetic model to a large value of $107 \mathrm{M}^{-1} \mathrm{~s}^{-1}$ or greater, we were able to model the equilibrium binding constant for amine to Cat $A\left(K_{b}=6.9 \pm 4.6\right.$ $\left.x 10^{5} \mathrm{M}^{-1}\right)$, the propagation rate constant for CatA $\left(k_{p}=783 \pm 18 \mathrm{M}^{-1} \mathrm{~s}^{-1}\right)$, and the relative ratio of CatA:CatB (1.4:1) in polymerization. Modeling using Copasi provides an objective value (sum of square deviations); herein, we obtain an objective value of $3.54 \times 10^{-12}$, indicative of a good fit between the model and experimental data. The rate constant for propagation obtained in this way is very similar to the value obtained by previous kinetic modeling work in our group ${ }^{4}$ and the ratio of diastereomers is similar to the $\sim 1: 1$ ratio observed by NMR. ${ }^{5}$ The experimental and fitted values for initial rates and active site counts as a function of the equivalents of amine added are compared in Figure S7 (also in the main text). Of note, we do not distinguish between inhibition of initiation and propagation in this kinetic model. At present, we do not have the requisite data to independently quantify inhibition of propagation and initiation. However, these data and this kinetic model clearly demonstrate the unique kinetics of the amine inhibition and support our hypothesis that one diastereomer of $\mathbf{I}(\mathrm{Cat} A)$ is more reactive towards alkene insertion than the other (CatB).

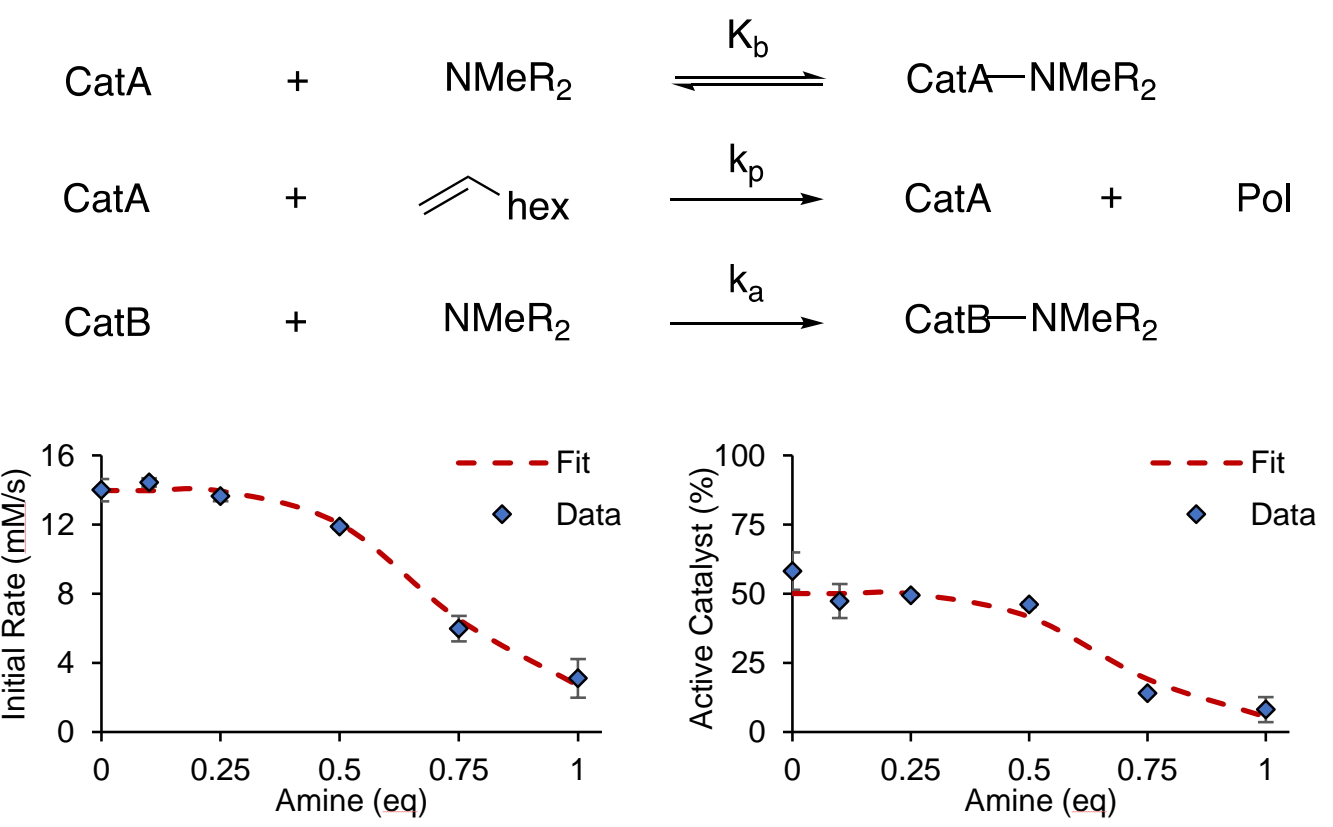

Figure S7. Two state kinetic model for amine inhibition in the polymerization of 1-octene catalyzed by I. (Left) Data (blue) and Fit (red) for the initial rate of 1-octene consumption vs equivalents of amine added to the activated catalyst solution. (Right) Data (blue) and Fit (red) for the active site counts vs equivalents of amine added to the activated catalyst solution. Data points are an average of duplicate experiments and error bars represent the standard deviation between duplicates. $\mathrm{k}_{\mathrm{a}}$ fixed at $107 \mathrm{M}^{-1} \mathrm{~s}^{-1}$ in this model. $\mathrm{R}=\mathrm{C}_{18} \mathrm{H}_{37}$ and CatA and CatB are the two different diastereomers of I where CatB is the "slow initiating diastereomer" and CatA is the "fast initiating diastereomer". 
Direct comparison of expected polymerization activity upon trityl activation in the presence of 1 equivalent of amine with observed activity following Brønsted acid activation in the 1-catalyzed polymerization of 1 -octene is informative. Although the ratio of amine: 1 is identical in the two scenarios, the polymerization rates are much different, as shown in Figure S8. The simulation line (dashed red line of Figure S8) was constructed for catalysis in the presence of 1 equivalent of amine relative to rac-1 by using kinetic parameters determined in the amine inhibition studies (see above). The observed consumption of 1-octene upon activation with ammonium salt (blue diamonds, Figure S8) represents catalysis in the presence of a single diastereomer of I. ${ }^{6}$ While there are some assumptions made for the kinetic model / simulations, these results clearly indicate a substantial difference in reactivity between the trityl activated / amine inhibited catalysis vs the ammonium salt activated catalysis.

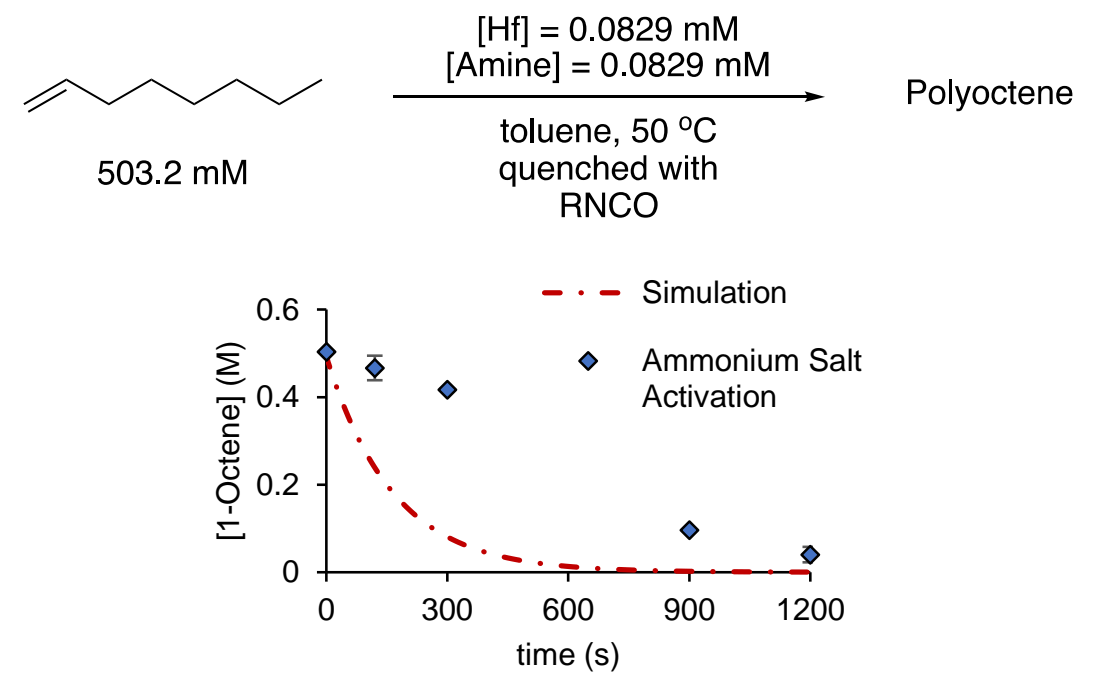

Figure S8. Comparison of the 1-octene consumption as catalyzed by rac-1. (Blue) 1-Octene consumption using rac-1 activated with [HNMe $\left.\left(\mathrm{C}_{18} \mathrm{H}_{37}\right)_{2}\right]\left[\mathrm{B}\left(\mathrm{C}_{6} \mathrm{~F}_{5}\right)_{4}\right]$. (Red) Simulation of 1-octene consumption (based upon previous kinetic model) using rac-1 activated with $\left[\mathrm{Ph}_{3} \mathrm{C}\right]\left[\mathrm{B}\left(\mathrm{C}_{6} \mathrm{~F}_{5}\right)_{4}\right]$ in the presence of 1eq of $\mathrm{NMe}\left(\mathrm{C}_{18} \mathrm{H}_{37}\right)_{2}$ relative to rac-1. 


\section{Raw Data Used for Kinetic Modeling}

Herein, we provide the raw data obtained for amine inhibition experiments that were used for the two-step kinetic modeling conducted in the previous section. A detailed procedure for these amine inhibition experiments is described above. The conditions used to obtain these data: [I] $0=$ $0.0000829 \mathrm{M}$, [1-octene $]_{0}=0.503 \mathrm{M}$, toluene $(1 \mathrm{~mL}), 50^{\circ} \mathrm{C},\left[\mathrm{NMe}\left(\mathrm{C}_{18} \mathrm{H}_{37}\right)_{2}\right]_{\text {varied, }}$, and the reaction was quenched with 2 eq of $\mathbf{3}$ (relative to I) after ten seconds.

Table S1. Data Used for Kinetic Modeling: [1-octene] $]_{t}$ [active catalyst $]_{t}$, and [amine]

\begin{tabular}{|c|c|c|c|}
\hline time (s) & {$[1 \text {-octene }]_{\mathrm{t}}(\mathrm{M})$} & [active catalyst $]_{\mathrm{t}}(\mathrm{M})$ & {$\left[\mathrm{NMe}\left(\mathrm{C}_{18} \mathrm{H}_{37}\right)_{2}\right]_{0}(\mathrm{M})$} \\
\hline 10 & 0.367 & 0.000044 & 0 \\
\hline 10 & 0.360 & 0.000052 & 0 \\
\hline 10 & 0.361 & 0.000043 & $\begin{array}{c}0.00000829 \\
(0.10 \text { eq relative to } \mathrm{I})\end{array}$ \\
\hline 10 & 0.357 & 0.000036 & $\begin{array}{c}0.00000829 \\
(0.10 \text { eq relative to I) }\end{array}$ \\
\hline 10 & 0.365 & 0.000041 & $\begin{array}{c}0.0000207 \\
(0.25 \text { eq relative to I) }\end{array}$ \\
\hline 10 & 0.369 & 0.000041 & $\begin{array}{c}0.0000207 \\
(0.25 \text { eq relative to } \mathrm{I})\end{array}$ \\
\hline 10 & 0.384 & 0.000039 & $\begin{array}{c}0.0000415 \\
(0.50 \text { eq relative to I) }\end{array}$ \\
\hline 10 & 0.385 & 0.000038 & $\begin{array}{c}0.0000415 \\
(0.50 \text { eq relative to I) }\end{array}$ \\
\hline 10 & 0.438 & 0.000012 & $\begin{array}{c}0.0000622 \\
(0.75 \text { eq relative to I) }\end{array}$ \\
\hline 10 & 0.449 & 0.000012 & $\begin{array}{c}0.0000622 \\
(0.75 \text { eq relative to I) }\end{array}$ \\
\hline 10 & 0.464 & 0.000009 & $\begin{array}{c}0.0000829 \\
(1.0 \text { eq relative to } \mathrm{I})\end{array}$ \\
\hline 10 & 0.480 & 0.000004 & $\begin{array}{c}0.0000829 \\
(1.0 \text { eq relative to I) }\end{array}$ \\
\hline
\end{tabular}


in situ Activation of rac-1 with $\mathrm{B}\left(\mathrm{C}_{6} \mathrm{~F}_{5}\right)_{3}$

a)

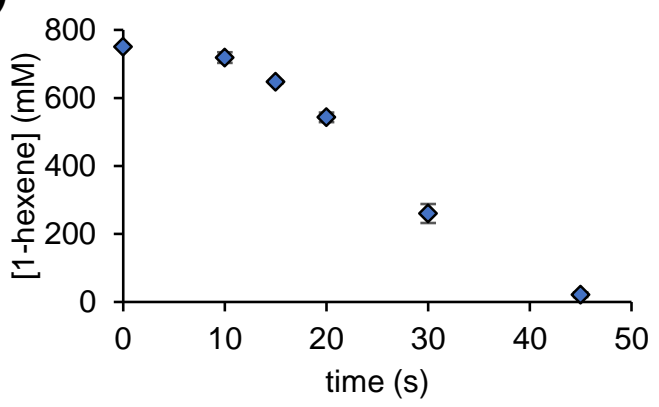

b)

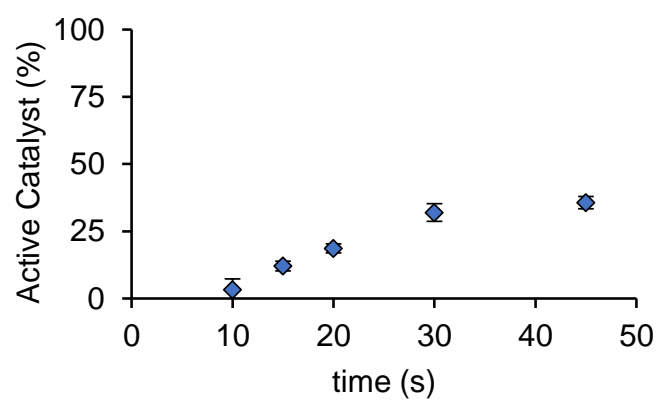

Figure S9. Polymerization of 1-octene catalyzed by rac-1 using in situ activation with $\mathrm{B}\left(\mathrm{C}_{6} \mathrm{~F}_{5}\right)_{3}$ as the activator. (a) 1-Octene consumption (b) Active site counts. Conditions: [rac-1] $=0.5 \mathrm{mM}$, $\left[\mathrm{B}\left(\mathrm{C}_{6} \mathrm{~F}_{5}\right)_{3}\right]=0.525 \mathrm{mM}$, [1-hexene $]=0.75 \mathrm{M}$, and toluene $(1 \mathrm{~mL})$ performed at room temperature and 2 eq of 3 were added to halt polymerization. Data points are an average of duplicate experiments and error bars represent the standard deviation between duplicates.

Molecular Weight Distribution Data for $2 / \mathrm{B}\left(\mathrm{C}_{6} \mathrm{~F}_{5}\right)_{3}$-Catalyzed Polymerization of 1 Hexene

Table S2. Temporal Profile of $\mathrm{M}_{\mathrm{n}}$ and PDI for the 1-Hexene Polymerization Catalyzed by $2 / B\left(C_{6} F_{5}\right)_{3}$

$\begin{array}{ccc}\text { time (min) } & M_{n} & \text { PDI } \\ 1 & 29,814 \pm 1,528 & 1.44 \pm 0.03 \\ 2 & 50,389 \pm 206 & 1.49 \pm 0.00 \\ 3 & 70,566 \pm 1,214 & 1.47 \pm 0.01 \\ 5 & 97,438 \pm 1,629 & 1.47 \pm 0.01 \\ 7 & 106,923 \pm 3,929 & 1.51 \pm 0.01 \\ 10 & 112,123 \pm 2,077 & 1.50 \pm 0.01\end{array}$


a)

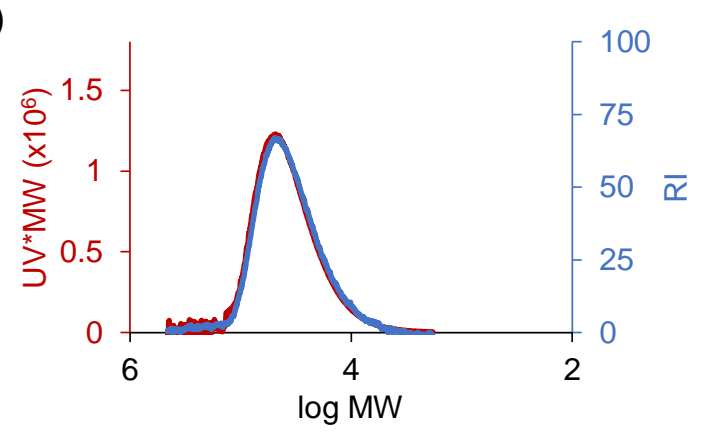

c)

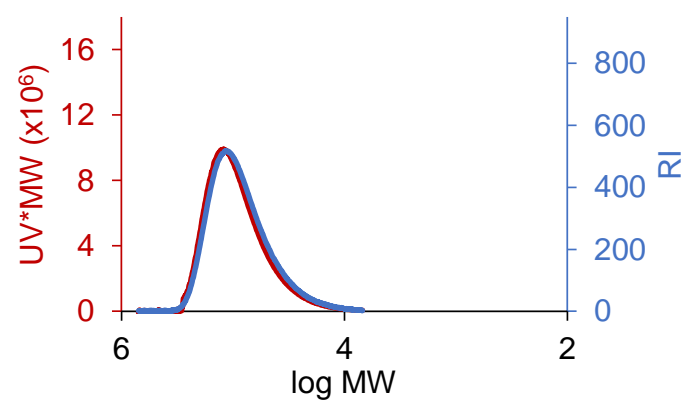

e)

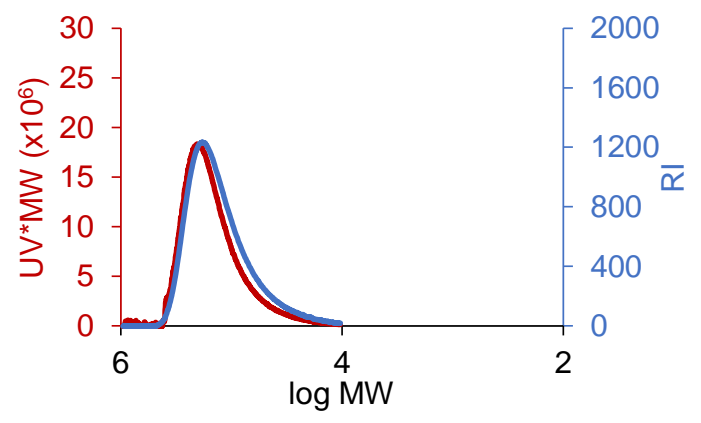

b)

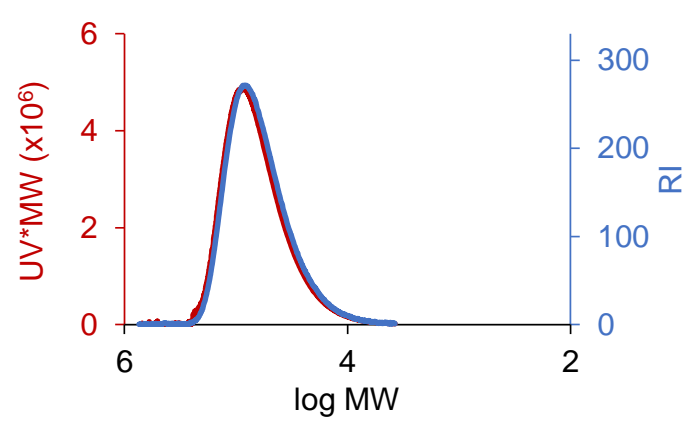

d)

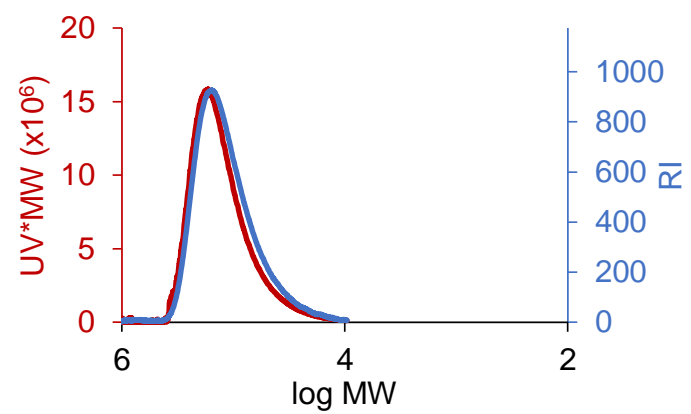

f)

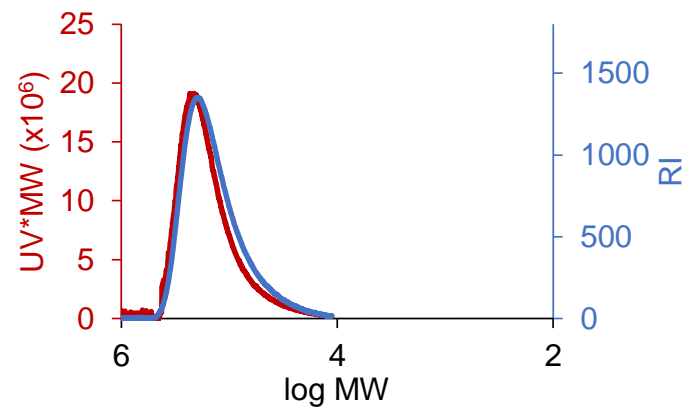

Figure S10. Molecular weight distribution data for the 1-hexene polymerization catalyzed by 2/B( $\left.\mathrm{C}_{6} \mathrm{~F}_{5}\right)_{3}$. Conditions: [2] = $0.50 \mathrm{mM},\left[\mathrm{B}\left(\mathrm{C}_{6} \mathrm{~F}_{5}\right)_{3}\right]=0.525 \mathrm{mM}$, [1-hexene] $=750 \mathrm{mM}$, toluene $(1$ $\mathrm{mL}$ total volume), $25^{\circ} \mathrm{C}$, quenched with 3 (2 eq relative to 2) to halt polymerization. UV-GPC traces in red and RI-GPC traces in blue. (a) UV- and RI-GPC trace of the 1-hexene polymerization quenched after 1 minute. (b) UV- and RI-GPC trace of the 1-hexene polymerization quenched after 2 minutes. (c) UV- and RI-GPC trace of the 1-hexene polymerization quenched after 3 minutes. (d) UV- and RI-GPC trace of the 1-hexene polymerization quenched after 5 minutes. (e) UV- and RI-GPC trace of the 1-hexene polymerization quenched after 7 minutes. (f) UV- and RIGPC trace of the 1-hexene polymerization quenched after 10 minutes. 


\section{References}

[1] Frazier, K. A.; Boone, H. W.; Vosejpka, P. C.; Stevens, J. C., J.US20040220050 A1. 2004. [2] Domski, G. J.; Eagan, J. M.; De Rosa, C.; Di Girolamo, R.; LaPointe, A. M.; Lobkovsky, E. B.; Talarico, G.; Coates, G. W., Combined Experimental and Theoretical Approach for Living and Isoselective Propylene Polymerization. ACS Catal. 2017, 7, 6930-6937.

[3] Nelsen, D. L.; Anding, B. J.; Sawicki, J. L.; Christianson, M. D.; Arriola, D. J.; Landis, C. R., Chromophore Quench-Labeling: An Approach to Quantifying Catalyst Speciation As Demonstrated for (EBI)ZrMe2/B(C6F5)3-Catalyzed Polymerization of 1-Hexene. ACS Catal. 2016, 6, 7398-7408.

[4] Johnson, H. C.; Cueny, E. S.; Landis, C. R., Chain Transfer with Dialkyl Zinc During Hafnium-Pyridyl Amido-Catalyzed Polymerization of 1-Octene: Relative Rates, Reversibility, and Kinetic Models. ACS Catal. 2018, 8, 4178-4188.

[5] Zuccaccia, C.; Macchioni, A.; Busico, V.; Cipullo, R.; Talarico, G.; Alfano, F.; Boone, H. W.; Frazier, K. A.; Hustad, P. D.; Stevens, J. C.; Vosejpka, P. C.; Abboud, K. A., Intra- and Intermolecular NMR Studies on the Activation of Arylcyclometallated Hafnium Pyridyl-Amido Olefin Polymerization Precatalysts. J. Am. Chem. Soc. 2008, 130, 10354-10368.

[6] Cueny, E. S.; Johnson, H. C.; Anding, B. J.; Landis, C. R., Mechanistic Studies of HafniumPyridyl Amido-Catalyzed 1-Octene Polymerization and Chain Transfer Using Quench-Labeling Methods. J. Am. Chem. Soc. 2017, 139, 11903-11912. 